\title{
TRES PANTOMIMAS DE RAMÓN GÓMEZ DE LA SERNA (LAS DANZAS): UNA LECTURA
}

\author{
Alessandra Verde
}

\section{Consideraciones preliminares.}

En el marco de las pantomimas, las Danzas de pasión, El garrotín, La danza de los Apaches, constituyen un objeto literario comparable con un prisma óptico en la medida en que permite interpretar las valencias, potencialidades y significados de los fenómenos visuales, pero también dinámicos y sonoros protagonizados por un sujeto humano. Ramón Gómez de la Serna declara necesaria la presencia del elemento femenino para que una obra pueda considerarse completa; en las tres Danzas esta presencia es fuerte y significativa. La mujer y, en términos más amplios, lo femenino, es en las Danzas el sujeto elegido para manifestar y desarrollar una interpretación peculiar y creadora de la realidad que se aleja de la uniformidad simplista de la imágen y alcanza la originalidad que supone el mirar "con ojos nuevos".

Las tres pantomimas analizadas tienen en común unos elementos estilísticos e interdiscursivos. En primer lugar el lenguaje sugiere la colocación onírica de los núcleos narrativos. Y en este sentido hay que subrayar una vez más que la(s) realidad(des) que el autor crea y describe no tiene(n) acceso a la realidad convencional del teatro en el cual tendrían que representarse. El fuerte contrasto de luz y sombra, el movimiento que origina reacciones emotivas y físicas, tienen un poder evocativo que la voz narrante manifiesta con violencia. De este modo se podría matizar quizás la observación a propósito de la irrepresentabilidad de buena parte del teatro de Ramón: hay en el texto una impresión de tridimensionalidad, característica propia de la visión directa y por lo tanto de la manifestación escénica también. La profundidad de perspectiva que es propia de las obras consideradas tiene una doble consecuencia: por un lado la acción "representada" tiene su tercera dimensión para el espectador intra-diegético (espectador-personaje) y para el extradiegético(espectador-lector); por el otro dicha profundidad de perspectiva es el resultado de una forma de mirar que la voz narrante elige y que responde a los planteamientos de Ramón. El lenguaje adoptado por el escritor refleja el enfoque dado al tratamiento de la realidad en sus aspectos de imagen y también de fenómeno físico. Ramón reivindicaba el valor del lenguaje y sus innumerables poderes en Palabras en la rueca (1911) a la vez que proponía 
"venerar palabra a palabra" la dignidad, la individualidad, la sexualidad de cada palabra, librada de la esclavitud etimológica y de la estaticidad en la que se ve relegada por los diccionarios. Se crean pues secuencias comunicativas verbales que "amplifican" el significado al dejar en suspenso una parte del mensaje (p.ej. al comienzo de Las danzas de pasión : "Subconsciencia de vivir ..../ Pleamar .../ Matemática ..."1 ) o al proponer arbitrarias asociaciones de palabras o imágenes (p.ej. "Adán y Eva, blancos con mucho ocre y mucho rosa, desnudos, largos, aguijonados, ...)" en el mismo texto.

Las tres pantomimas consideraradas aquí son de 1911 y se publicaron junto con otras obras (algunas de ellas ya editadas en Prometeo) en la revista Tapices en el año '13.

La tres "danzas" tienen unos importantes elementos en común, y sin embargo cada una de ellas constituye un núcleo narrativo a parte y propone una realidad dinámica con características propias. Por esta razón creo oportuno observar previamente cada una de las tres "danzas" y luego reflexionar sobre eventuales aspectos comunes de las mismas.

La relevancia de la música en las tres obras sugiere la relación con su rol primario en la sensibilidad de fin de siglo, en el Decadentismo hasta el desarrollo de la música del XX.

\section{Las danzas de pasión.}

La obra está dedicada a Rafael Cansinos Assens de quien Gómez de la Serna subraya las artes de "judío sabio en cabalística" destacando así sus dotes originales; sin embargo cabe recordar que por cábala no sólo se entiende la tradicional interpretación de la Escritura sino también la posterior práctica supersticiosa que combina letras ebraicas con palabras del Antiguo Testamento. En los dos sentidos se trata de todas formas de una actividad decodificadora para llegar a un significado que el Autor brinda al 'iniciado' Cansinos Assens.

Las danzas de pasión se desarrolla en una atmósfera onírica, con fuertes presencias simbolistas, a la que contribuye la muy reducida presencia de referencias espaciales y temporales que puedan remontarse a convenciones reales. La acción tiene lugar en el marco de un teatro oscuro. La descripción presenta, -simultaneizados-, todos los elementos que constituyen estructura material y atmósfera del teatro donde se encuentra el público representado como una máscara grotesca ("boca grande y belfuda"); sólo hay dos palcos y en ellos la personas son figuritas emblemáticas : una mujer "con un sombrero inverosímil", su empresario que oculta su brutalidad detrás de una mirada tierna y un joven aspirante a tener una doble identidad (una para los artistas que le miran y otra para el público) como Jano. En la platea los espectadores están pensando cada uno en sus problemas, aspiraciones y deseos; de ellos Ramón describe los sentimientos esbozados -olvidar un amor, trabajar por él, engañar, etc.- que confluyen en la imagen de la escena : Adán y Eva, cogidos de la mano.

Los protagonistas de la representación aparecen sin previa advertencia, inmediatamente connotados por su inocencia desarmante, enmarcada en un cuadro escénico digno de una

\footnotetext{
${ }^{1}$ R. Gomez de la Serna, Las danzas de pasión, en Tapices , Madrid 1913.
} 
"tabla primitiva". En esta Danza se reitera, como concepto positivo, la sencilla desnudez de Adán y Eva, en medio de una naturaleza virgen que ignora toda ciencia. En esta linea se realiza una oposición entre el teatro y la 'tabla primitiva' puesto que el primero representa "el eclectismo" y la segunda "la unidad". Ramón hace de esta pantomima la reivindicación de la pureza ab initio que permite a Adán ser "joven por paradoja" junto con Eva. Los dos, retratados con una mezcla de estereótipo y atrevida metonimia (Eva es rubia y de cuerpo redondito, y los dos son "aguijonados"), comparten la intocable inocencia que los distingue hasta en el aspecto cromático "blancos, con mucho ocre y mucho rosa". Se vuelve a subrayar la importancia del elemento femenino, puesto que Adán tiene la misma feminidad de Eva. Esta característica, aparentemenete poco relevante, se hace más significativa cuando, al leer La danza de los Apaches se observe como lo masculino se hace sinónimo de brutalidad, de un instinto de creación tan violento que llega a la destrucción inapelable. Sin embargo aquí, en Las danzas de pasión, nada subraya la distinción de los sexos ${ }^{2}$ sino que el candor de Adán y Eva los uniforma y elimina todo contraste entre ellos. Las dos figuras se caracterizan por su total inmovilidad y su silencio; sin embargo esto no les impide encarnar eficazmente los ideales -y digo 'ideales' porque como tales los presenta Ramón en un atmósfera también ideal- de pureza, mundo primitivo, unión de hombre y mujer gracias a su ingenuidad.

En esta breve pantomima la voz narrante introduce la conclusión unificando ámbitos muy amplios: "Las diversidades de la vida y del Teatro se borran" ; sin embargo no especifica si la 'vida' a la que hace referencia es la vida considerada desde el punto de vista de los espectadores de la pantomima, es decir una vida que el lector colocaría en la ficción intentando matizarla a partir de los recursos que el texto ofrece; o si en cambio hablando de 'vida' se hace referencia a la experiencia extratextual y extraliteraria también; en este segundo caso y en razón de la presión que llegaría a ejercer sobre el lector, el texto resultaría dotado de capacidad centrípeta. La ambigüedad o, mejor dicho, la doble posibilidad de intrepretación se refuerza ya que surge la inquietud delante de las consecuencias del pecado original $-" ¡ H a n$ sido arrojados del Paraíso!"- ; sigue la exclamación la propuesta de rescate expresada con una forma impersonal: "Se piensa para indulgencia plenaria"; ¿quién está y quién podría estar detrás de este 'se'? En un país de cultura católica el pecado original constituye un elemento de referencia fundamental. Por tanto el impacto sobre el público-personaje o el lector también se prefigura inmediatamente; Adán y Eva sin embargo nunca están definidos como pecadores, ni se nombra el pecado y menos aun la culpa; y hay una razón evidente para ello: los dos son puros e inocentes, no conocen siquiera la existencia del pecado, ni su naturaleza; por lo tanto lo que hagan no podría oponerse al 'Bien' ni ser juzgado a partir de una categorización moral. Pero también se nos ha advertido que estamos delante de "todos los problemas humanos retraídos a Adán y Eva" ; la identificación acerca y autoriza el perdón a los humanos porque se justifica al hombre con un motivo casi pascaliano: al proponer indulgencia resulta que "todo se explica como necesidad del Paraíso"; la nostalgia del trono

\footnotetext{
2 A este propósito de la feminidad de Adán se puede recordar el inciso "¡Oh, qué conmovedor es saber lo cierta que es esta gran feminidad de todos los hombres, y qué duro es olvidarla!"
} 
del hombre pascaliano se reconoce a posteriori y se materializa en la añoranza de la tabla primitiva de Adán y Eva arrojados del Paraíso. La inquietud del Paraíso encuentra consuelo sólo en el socorro de Eva, mujer presente en todas las mujeres y por lo tanto verdadera y real.

El teatro deja de ser un marco físico, desaparece y en él quedan solamente una luz perfecta y los dos jóvenes de naturaleza vegetal que en sí tienen su razón de ser: una vez más la tabla primitiva lo representa todo, con su bosque primordial sin perspectiva, en el cual Adán y Eva están en perfecto equilibrio.

La escena origina la sorpresa de las mujeres, las que viven en el mundo de las convenciones sociales, víctimas de la palabra codificada, y de las descripciones didascálicas de los hombres. Una reducción espacial deja paso a lo que en realidad es el inicio de las danzas de pasión: en un escenario muy pequeño y muy oscuro se encuentran mujeres sobrenaturalmente altas; no son ellas las que danzan sino que las danzas comienzan dentro de ellas. Las danzas quedan, por lo tanto algo misterioso, íntimo y profundo; lo 'no dicho' se caracteriza como "lo indecible', consecuencia natural del retorno a la naturaleza primitiva y es algo secreto que tiene su razón de ser en sí, en el instinto, en una oscuridad que no se puede alumbrar ni transformar sino simplemente aceptar, al ser inaccesible.

El texto, desde un ámbito colectivo llega a un espacio individual pasando por la representación emblemática de los seres humanos en el status primordial, Adán y Eva.

La imagen final de las mujeres en la pequeña escena oscura, aparentemente desconectada de la representación de la 'tabla primitiva' es en realidad la consecuencia de todo lo que en ella tenía lugar; a pesar de la realidad en la que los hombres mienten por descuido o superficialidad, las danzas de pasión son posibles en esas mujeres que comparten con Adán y Eva el misterio interior y un elemento físico (Adán y Eva son aguijonados; las mujeres son sobrenaturalmete altas). Todo vuelve como atraído sin posibilidad de desviación y por manifestación natural a una pureza no moral sino esencial y originaria.

\section{El garrotín ${ }^{3}$}

La obra desarrolla una original descripción e interpretación de la música utilizando como sujeto expresivo a la mujer. Los dos elementos intrumentales de la pantomima son pues la música y la mujer que unidos por la capacidad dinámica de ambas permiten la multiplicación de los significados de la imagen y del sonido.

El Garrotín es una celebración del movimiento, creador de espacio y capaz de desvelar significados profundos al que sepa percibir la experiencia que supone. Al ser éste el fin perseguido, es ausente cualquier referencia a la identidad de la mujer que baila el garrotín; es importante, en cambio, ver como el movimiento, al dar vida al ser humano, descubre su desnudez, es decir la plasticidad esencial y animal (por lo tanto auténtica) del sujeto. A partir

\footnotetext{
${ }^{3} \mathrm{El}$ título hace referencia al baile, en voga a finales del siglo XIX.
} 
de las descripciones críticas hechas por el Autor de distintos objetos se pueden esbozar una contraposiciones significativas:

$\begin{array}{lcc}\begin{array}{l}\text { dinamicidad } \\ \text { movimiento } \\ \text { (danza) }\end{array} & \begin{array}{l}v s \\ v s\end{array} & \begin{array}{c}\text { estaticidad } \\ \text { inmovilidad }\end{array} \\ \text { desnudez } & \begin{array}{l}\text { ("Sórdidas Venus desnudas de los museos") } \\ \text { ("absurdamente vestidas, por quietas,") }\end{array} \\ \text { vida } & \begin{array}{l}v s \\ \text { "traje pesado" } \\ \text { (de "las Venus") }\end{array} & \begin{array}{l}\text { muerte } \\ \text { ("Sórdidas muertas bellísimas que } \\ \text { no podrán soportar el desnudo) }\end{array}\end{array}$

La secuencia de relaciones que desde el movimiento llega a la afirmación de la vida por oposición implícita a la muerte simbolizada por la inmovilidad llevaría al concepto de impulso vital como punto de llegada; creo, sin embargo, que sería simplista reducir de este modo la multifacética realidad creada en el texto; en El garrotín hay, una exaltación del movimiento que exalta la carnalidad, la expresión del cuerpo interpretado fuera de los esquemas convencionales, pero el sensualismo que se origina nace de un proceso de introspección dentro de la mujer protagonista del baile que el Autor relata cumpliendo una función de mediación y entonces de filtro interpretativo. Aclaremos las circuntancias de los segmentos narrativos. La narración se abre con el inicio de la música (un "largo solo") que crea un plano escénico al que se sobrepone, después del planteamiento del valor del movimiento frente a la inmovilidad, la figura de la mujer. Se anuncia el comienzo de la 'acción' y se define el baile: "Danza de introspecciones ...". Inmediatamente la danza llega a ser la expresión del placer, una manifestación de éste. No sólo se trata de la reafirmación de los sentidos sino también de la afirmación de su poder en el ámbito de la memoria inconsciente:

"Se alzó con la concepción del garrotín como si lo hubiese bailado, después de esa inspiración secreta, y sublunar que la rindió en el aprendizaje..."

El garrotín ya no es simplemente un baile, ni un pretexto para la evocación sino que la dirección de la narración invita a interpretar de forma exponencial la palabra: del garrotín se ha llegado a "la concepción del garrotín". He aquí la teoría ramoniana de la palabra que se desarrolla no sólo en la vertiente puramente lingüística de subversión y recreación de la cadena sintagmática (pensemos en los atrevimientos interpretativos propios de las greguerías y también en las oraciones inacabadas de la prosa ramoniana) sino también en la edificación de un mundo referencial y comunicativo sorprendente en donde la secuencia verbal se enriquece y se amplifica. 
La mujer y cada parte de su cuerpo encuentran a sí mismos en el baile: no es solamente un reconocimiento sino la agnición de la identidad del sujeto que tiene como punto de referencia el "instante de tenuidad y de cristalería en que se vidrian los ojos y la carne". Ese instante no contempla la posibilidad de la mentira o de la innaturalidad; de forma que el garrotín, íntima evocación de aquél instante, es imagen de íntima naturalidad ${ }^{4}$. La referencia al sexo no queda falta de la valorización de la creación en cuanto maternidad. Si por un lado se especifica que el garrotín se concibió como "una cosa pasada que madura" por otro lado, el paralelismo sugerido hace que se diga que es "cosa del décimo mes". En esta pantomima Ramón, al ritualizar en el baile el placer sensual, reivindica la presencia de éste como premisa de la maternidad; tanto es así que, haciendo referencia en las lineas siguientes a la figura del hijo, afirma que el baile de la mujer protagonista del garrotín se convierte en flor mientras que para otras mujeres fue fruto, y un fruto que se ha hecho objeto sólido sin que la madre haya conocido el placer del baile.

Ramón ofreće entonces la clave de lectura de El garrotín; no se trata solamente, como ya se ha dicho, dẻ una exaltación sensualista stricto sensu, ya que la libre expresión física abarca también el universo espiritual: "Jugando el cuerpo por entero, en sus fisuras más recónditas, se salva también el alma."

El garrotín parece relatar una liberación pues, a través del baile, la música tiene resonancias en "los huesos destetanizados"; ya sin rigidez se pasa del prestissimo, al pizzicato, al scherzo, para llegar a los allegros furiosos . Liberación, ruptura, poder exhuberante que devuelve vitalidad al cuerpo humano convertido él mismo en instrumento musical que emite una infinita variedad de notas.

Como en una sucesión febril de escalas cromáticas cada vez más complejas el cuerpo cumple su metamorfosis creadora de vitalidad. Una serie de imágenes, que recuerdan las tomas cinematográficas muy acercadas al objeto, retratan a la mujer que baila. Como fotogramas reunidos, -entre la sincronicidad del movimiento y la progresión secuencial de la focalización-, las distintas instantáneas capturan el gesto y al mismo tiempo retratan las partes del cuerpo de la mujer haciendo de ella un personaje colectivo en sentido épico ${ }^{5}$. Ella, a través de la fragmentación, se hace criatura íntegra a medida que cada miembro de su cuerpo interviene y participa del movimiento. La fuerza fluye en sus piernas como linfa vital; los pechos, "pechos y no senos" son fuertes y delicados a la vez y se carcacterizan por su "blancura abrasadora de nieve"; sin embargo este oxímoron que se remonta a la tradición cortés se aplica como recurso estílistico para afirmar un principio vital y la total inocencia y naturalidad de la mujer. Además la imagen oximórica no está aquí para ejemplificar el tradicional amor-fuego sino el fuego-vida, y esto gracias al uso original que hace Ramón del instrumento metafórico.

\footnotetext{
${ }^{4}$ Recordemos el significado de desnudez ,naturalidad y naturaleza desarrollados en Las danzas de pasión.

5 Véase, a este propósito,_Las danzas de pasión donde todas la mujeres se encarnan (verbo utilizado por Ramón para designar la naturaleza de su teatro) en prototipo eterno de Eva.
} 
Por otra parte el incendio transforma en llamas todo el cuerpo de la mujer; la minuciosa descripción se detiene también en las manos y los dedos ("son lo más pánico y flamígero") captando la semejanza entre ellos en movimiento y una llamas 6 .

Tras una pausa en la que el fuego se apaga y la mujer se abandona agotada, la llama se reaviva y entonces la imagen de los ojos, sólo esbozada anteriormente, vuelve. Ramón dice que en el garrotín los ojos de la mujer, "téngalos azules, rubios ó verdes, se hacen ojos sarracenos, la pupila negra, $\langle\ldots\rangle$, violados por el paso circular de color del blanco al negro, mucho blanco en extensión y mucho negro en densidad y en hondonada; un negro prolongado como un túnel, $\langle\ldots\rangle$; una tilde desconcertante que se hace irresistible de blancor atunelada de negro...". Evidentemente la fuerza de la descripción reside en la impresión de impacto resultante del contraste blanco $v s$ negro. El uso que se hace de estos dos colores en las pantomimas analizadas permite marcar límites, perfiles y contornos de forma plástica y de la misma manera vemos como, en la descripción de los ojos a cada uno de los dos colores se atribuye la función de representar una dimensión; la del blanco es extensión (horizontalidad), la del negro profundidad (verticalidad). Y si a estas dos dimensiones atribuímos el movimiento el resultado será una visión en perspectiva, es decir una imagen plástica. A su vez la imagen plástica no sólo es compatible sino que es propia de un contexto escénico, es decir que se sitúa perfectamente en el terreno de la pantomima. El color, utilizado para crear el contraste se revela entonces elemento funcional a la coherencia interna del texto.

Perfectamente equilibrada es la sugerente imagen decadente de la mujer que levanta los brazos y descubre las axilas; sin reproducir aquí por completo la riquísima adjetivación ofrecida por el autor, merece quizás la pena recordar que se definen "las que muestran $\langle\ldots\rangle$ lo selvático de la mujer y como es un fruto sobre el suelo, áspero, real, sabroso á tierra y humedad de tierra, muy silvestre y muy áspero"; es inmediata la relación con algunos de los motivos dannunzianos : desde "le rugiadose violette", de la amada en Il piacere, a la mujer vegetal de la conocida lírica La pioggia nel pineto ${ }^{7}$.

En Ramón no se encuentra, evidentemente, la valencia de voluptuosidad que caracteriza al poeta italiano, sino más bien una distinta extremidad, más espontánea y brillante que no

\footnotetext{
${ }^{6} \mathrm{El}$ crítico ejerciendo su oficio y el lector cumpliendo el acto de lectura han observado y observan en Ramón su gran riqueza léxica; sin embargo ésta no ha de considerarse simplemente consecuencia de la exuberancia multifacética del autor madrileño; en éste, como en muchísimos otros casos, la palabra elegida, (y no solamente escogida), hace posible una "excedencia de semanticidad" que enriquece el texto y su capacidad evocativa: "flamígero" no es "llama" ni "llameante"; es una palabra que contiene en sí los dos semas de fuego, llama (flamma) y de llevar (gerere). Es decir que la atribución dada a las manos de la mujer-ser en movimiento pertenece a la misma constelación semántica de lo dinámico.

7 Particularmente significativos en relación con el tetxo de Ramón me parecen estos versos de la lírica citada (vv. 52-64): " E immersi/ noi siam nello spirto/ silvestre,/ d'arborea vita viventi;/ e il tuo vólto ebro/ è molle di pioggia/ come una foglia, / e le tue chiome/ auliscono come/ le chiare ginestre,/ o creatura terrestre/ che hai nome/ Ermione." Y también los vv. 99-101" ....; non bianca/ ma quasi fatta virente,/ par da scorza tu esca.", donde scorza ha de leerse, como comenta entre otros F. Roncoroni, 'corteccia di un albero', es decir corteza de un árbol'. G. D'Annunzio, Laudi, ed. Mondadori, (Milán 1983 ). D'Annunzio las compuso entre 1903 y 1912.
} 
se contempla a sí misma en sublime edonismo; Ramón abre camino a la creación de un mundo nuevo, buscando y desvelando el vigor vital que en él late.

Revelada gracias al movimiento, la desnudez y con ella la carnalidad y el vigor vital se expresan en la reiteración del 'climax'. Y en el momento en que todo el cuerpo ha recobrado su fuerza instintiva, es cuando la voz de ese narrador omnisciente dice por fin que la cabeza de la mujer es "más inclinable, más indefensa, más seducible que nunca". Es decir que sólo una vez librada su vitalidad el cuerpo se revela seductor; se trata pues de 'seduccion vital' que todo lo abarca apasionadamente: la lengua, la nariz, los oídos que "son como dos uvas ácidas y blancas"8.

La experiencia del baile es una experiencia extrema, que permite la revelación de una segunda identitad de la mujer, la secreta, el 'yo' auténtico que no está sujeto a las convenciones del mundo controlado propio de la realidad.

La música termina y contemporáneamente se abre un panorama de olivos que, se dice, es propio para toda figura de odisea. La mujer es la figura de odisea y, como Ulises, ha vuelto a sí misma tras un largo viaje en el cual ha conocido el límite de sí; los olivos también pueden considerarse como una evocación del Evangelio, "símbolo trágico, $<\ldots . .>$ del antiguo apasionamento de la tierra, que nadie mejor que la mujer podía anunciar". He aquí la mujer hecha perfecta representante de una pasión que es, a la vez, sacrificio, fertilidad (tierra), misterio, cuerpo.

Sólo ahora, al términar la pantomima, la misteriosa voz narrante afirma que éste es el baile de la mujer.

Ha tenido lugar dentro de ella un proceso misterioso que llega a su ápice cuando la mujer se hace madre de sí misma, fénix, al ser descrita primero como muerta e inmediatamente después en la postura de una recién nacida.

Muerte y re-nacimiento hacen evidente la descripción simbólica de un ritual catártico en el cual el yo se afirma también en cuanto gozo de sí mismo; dentro del proceso de purificación que supone para "ella" bailar su propio destino, se ha afirmado también el narcisismo de la mujer; a través de la 'danza' experimenta un "sentir" absoluto, total y sorprendentemente suyo.

Ramón no contempla la liberación (sensual stricto sensu) de la mujer en relación con la sociedad sino más bien frente a ella y fuera de ella. La mirada con "ojos nuevos" no observa la realidad para cambiarla sino para ver otra, radicalmente distinta.

\section{La danza de los apaches.}

Atmósfera nocturna, referencia explícita a París y al ambiente bohemio de los locales fumosos, el mundo de la calle son los primeros y fundamentales matices que introducen la

${ }^{8}$ En el poema citado D'Annunzio compara los dientes de la mujer con frutos de almendro : "i denti negli alvèoli/ son come mandorle acerbe"; op. cit. vv. 108-109. 
danza. Esta es la "java" que se contrapone al garrotín por ser en las mismas palabras del Autor "la danza del hombre" el "apache" parisino de principio de siglo. También aquí se encuentra la pasión pero se trata de "dureza de la pasión reprimida" y por lo tanto falta en esta danza que, de las tres analizadas, es la más rica en resonancias simbolistas, cualquier relación con la capacidad libertadora y vitalista del Garrotín.

La fascinación de lo nocturno, subterráneo y violento se origina gracias a la evocación de un viaje a París que la voz narrante refiere a sí misma y que, teniendo en cuenta la estrecha y simbiótica relación entre Ramón y su obra, se puede justificadamente identificar con uno de los viajes a París de Gómez de la Serna ${ }^{9}$. En la escena que caracteriza el inicio de este texto destacan elementos típicos del 'fin de siglo': el mismo tema del viaje ${ }^{10}$, la exaltación de la mujer nocturna y callejera frente a las mujeres elegantes y refinadas, el malditismo bohemio que penetra la escena, no real todavía sino sólo esbozada a través de las agudizadas capacidades receptoras de los sentidos.

Todos los elementos ejercen un poder magnético y misterioso; entre ellos destaca la mujer que lleva un antifaz negro, símbolo importante en la obra de Ramón. La mujer que lo lleva revela inmediatamente su identidad connotada por el dolor y la violencia sufridos en cuanto víctima de un sacrificio inicialmente inexplicable perpetrado por el hombre.

Manifestando una sensibilidad casi tremendista la descripción del cuerpo martirizado de la mujer es pretexto para la exaltación de una belleza totalmente original en contraste con las obligaciones de lo positivo regido por la moral convencional.

En la misma linea también los colores -cuya capacidad en este sentido se ha destacado anteriormente- van creando la profundidad de una forma muy exacta. En primer lugar el Narrador dice que el sujeto "en fantasía de color tiene las genialidades más brutales de lo trágico"; valga el ejemplo del empleo del color rojo de la boca de la mujer, boca que está herida y a la vez "es" una herida ella misma; y también poco más arriba, al describir los cardenales en el escote y en los brazos de la Polaire, se dice que las señales de los golpes tienen "colores de excepción, $\langle\ldots .$.$\rangle , que en el verde aventajan ese verde que deja el mar$

\footnotetext{
${ }^{9}$ Probablemente de 1909.

${ }^{10}$ Luis García Montero lo analiza detenidamente en Poesía, cuartel de invierno Hiperión, ( $1^{\circ}$ ed. Granada 1987). Abriendo su reflexión a partir de "Ligeia, reflejo femenino de la perfección", el poeta y estudioso granadino recorre los caminos del 'viaje' destacando el valor que éste adquiere en los poetas malditos "quienes delimitaron definitivamente el tema del viaje" (pág. 12); y lo define con palabras que se pueden aplicar al texto que nos ocupa "como forma de encuentro con la propia subjetividad, aparecida siempre, único puerto de llegada"; este "puerto de llegada" es para la mujer de las pantomimas alcanzado con la intervención, imprescindible, de los sentidos. Hay otra afirmación de García Montero que me parece aplicable a la figura femenina de la Pantomimas : "Sólo un sujeto escindido puede viajar a través de sí mismo, o más aún, puede sentir la necesidad de viajar" (pág. 17). Se trata en nuestro caso de un viaje interior, con aspectos oníricos si observados desde fuera del sujeto, mientras que para él se trata más bien de sorprendentes descubrimientos debidos a la introspección que es ella misma un viaje inquietante y a menudo inevitable.
} 
como musgo en los rincones obscuros de los fiords y que luce en la obscuridad de las grutas extrañas ..." 11 .

El núcleo fundamental del texto se pone de manifiesto muy pronto, al prinicipio del mismo: las consecuencias de la violencia sobre un cuerpo, la agresión -aceptada por la víctima, es importante recordarlo- origina en el sujeto (la Polaire) una transformación que se desarrolla hacia el "límite", con una ex-centricidad estética tan marcada que, debido a la extremidad de la manifestación narrativa ramoniana, inhibe en el receptor el mecanismo de espontánea empatía ${ }^{12}$ hacia el otro que sufre. Todo esto se podría resumir quizás diciendo que puede que falten de verosimilitud el 'contexto' y/o los núcleos narrativos del 'relato' y que por tanto se origina un justificado distanciamiento entre hechos narrados y receptor; sin embargo no me parece tan simple pues no hay falta de verosimilitud aunque pueda parecerlo sino que hay más bien un desajuste descriptivo y de valoración respecto a la convención común. Este desajuste, a fin de cuentas vuelve a conducir a la ex-centricidad estética: "¡Oh! La Polaire más estilizada, más hechas sus caderas, suavizadas por una graciosa relajación, más imaginarios sus pechos, reformada su flojedad, por influjo de las contusiones y de la enfermedad latente, llena de sadismos intravenosos, formidables, afilados y poderosos para hallar las más bellas y las más raras substituciones de la mediocridad ....".

La mujer sale pues de la mediocridad al hacerse entre las manos de su apache materia labrada hasta resultar convertida en un objeto digno de análisis estético. El espíritu decadente se manifiesta entonces de forma tangible pero se caracteriza también por la originalidad que adquiere en Ramón Gómez de la Serna; ha sido asumido, metabolizado y ahora se expresa de forma vital sin limitaciones; no se centra elitariamente en lo sensual y exquisito sino que se concentra en los sentidos y en la intensidad de la percepción del iniciado delante de cualquier manifestación.

Como todo objeto fruto de un trabajo artístico la mujer-materia (golpeada y herida) encierra en sí interrogantes, preguntas referidas al proceso de creación del objeto final. Así el mismo apache es mano creadora sin conciencia de su proprio poder y al mismo tiempo víctima de la realidad que llega a promover con sus actos. El hombre, simplemente, ha golpeado a la mujer y el resultado, que sobrepasa sus intenciones, es una forma asombrosamente nueva en la persona de ella. El nuevo objeto procede pues de las manos de quien ha moldeado en formas distintas su materia original pero las modificaciones operadas por el apache han sido ciegas porque él ignora la identidad íntima de la substancia que es la mujer. La voz narrante se hace más profunda e hipotiza sobre los posibles procesos que han dado vida a la mujer-materia, busca los secretos de la mujer que son secretos de la muerte y resurrección : "¡Así era de obscuro el encanto de la Polaire, aglomerado de quizás! ...Quizás tenía el encanto desesperado é insólito de haber estado en La Morgue y

\footnotetext{
11 Se puede destacar aquí que el segundo término de la comparación con los elementos atributivos de la mujer es otra vez la tierra, aunque la relación Mujer-Tierra resulta aquí bien distinta respecto a la identificación positiva de la danza anterior.

12 En sentido amplio.
} 
haber podrido y fermetado y dramatizado allí su belleza, una gran belleza normal, <...> Quizás había pasado unos días en el fondo del Sena, completamente deshecha y reblandecida 13, como se reblandece el barro seco de los bocetos antiguos para poder formar los nuevos y construir, con un deseo calenturiento, la obra magna.".

Los pasados luctuosos y macabros que podrían haber precedido la nueva realidad de la Polaire forman parte del ritual de re-creación que tiene algo inexplicable y supra-real (que sí se concretiza en una imagen surrealista): la mujer ahogada sale del agua viva y se arregla discretamente el pelo, respondiendo al deseo del amante que la ha asesinado. El amante asesino, figura emblemática del hombre, violento por naturaleza, tiene el anhelo subyacente de ver nuevamente viva a la mujer que ha matado y pretende encontrarla cambiada hasta encarnar el ideal ilusorio que lo ha empujado al delito.

El asesino pues actúa con una intención catártica y la Polaire es la privilegiada críatura que reune en sí cacterísticas negadas a otras; ella ha pasado por la tragedia, ha vivido la destrucción sin conocer la aniquilación sino llegando a una nueva vida y el drama ha dejado en ella una intensidad física que la distingue y la hace única, modelo de sí misma.

Se vuelve al "teatro de la obra", al ambiente escénico. La muerte, el ápice de la tragedia (y, según Cesar Nicolás, el eje temático en Gómez de la Serna), así evocados conducen a una conclusión que revela el trayecto circular seguido en la disposición de la materia narrativa.

El desfase de planos espaciales se hace aun más importante al 'aparecer' la música, hasta ahora ausente en la narración, pero que se hace de repente motor de la acción en el citado "teatro de la obra". La música hiere el pecho a un público mudo que se nombra ahora por primera vez y que actúa de coro silencioso a la tragedia, sufriendo también en ella.

En la escena, aunque no se describa como tal ni se delimite su espacio, la mujer y el apache, "él", están bailando. Es el hombre quien guía el movimiento, controlando de forma absoluta cualquier emoción. El apache niega toda expresión de solidaridad o enamoramiento durante el baile que ve a la mujer no sólo sumisa sino totalmente entregada a él, a su voluntad, dispuesta a ser simulacro renunciando a la autenticidad pues el hombre quiere más el primero que la segunda y ella no puede ser sino víctima dispuesta al sacrificio. Al afirmar su poder sobre la mujer, el hombre la destruye sin remedio y en la desolación de la aniquilación del yo ahonda sus raices el nuevo símbolo que la mujer encarna: el dolor de cada uno, los momentos concretos de agudo dolor, las heridas inconfesadas y nunca olvidadas que toda persona (incluso el público y quizás el público-Lector), ha (¿hemos?) vivido.

Como las mujeres de Las danzas de pasión, dobladas sobre su misterio interior; como la mujer de El garrotín en su inconsciente triunfo biológico, también la "golfa contusa" custodia un secreto imperscutable: sus senos. Lo que guarda el pecho de la mujer es

13 La imagen de la mujer en el agua evoca a la Ofelia de John Everett Millais, pero ésta es una joven fluctuante y casi incorpórea mientras que la Polaire está en el fondo del Sena y su inocencia será una conquista posterior consecuente al sacrificio, rescate debido al sufrimiento pero que no le proporciona paz. 
inalcanzable; "¿Qué fatalidad no hay en ellos?". Se trata de un "misterio insoluble" que nadie sino la mujer puede conocer, y que el hombre desconoce. Torpemente no hace más que seguir con su agresión.

Soledad absoluta, maternidad-dolor, nuevamente infligido por el hombre, "matriz deshecha " del sujeto; la mujer que Gómez de la Serna retrata en las pantomimas es víctima sacrifical, encierra un misterio antiguo, nunca se levanta en contra del rol que ha sido obligada a sostenener. Por otra parte cabría preguntarse si, en las tres pantomimas analizadas, se puede hablar acertadamente de mujer como símbolo de la resignación. Hacerlo me parecería un poco atrevido. Partiendo de la identificación de la mujer con su vida biológica animal y su 'élan vitale', aunque se hable en más de una ocasión de la dimensión espiritual, no cabe duda que ésta última está relacionada estrechamente con lo que dicta la vitalidad física, la vivencia y supervivencia del animal o del vegetal que persigue su propia conservación. Y es más : la dimensión espiritual abarca pero no se centra en la dimensión intelectual; quizás porque ésta supondría la verbalización de lo que el Autor afirma incognoscible: el "secreto".

La bailarina se pega al apache "como al confesionario" sumisa, sacrificada, consciente sin embargo de haber proporcionado al hombre lo que él quería.

Depués del "baile del hombre" "éste vuelve a sus crímenes más sereno y saludable" y la mujer vuelve "a su vida" conciente de su propio sacrificio y de que el apache es su "discípulo" y no su dueño.

El texto evoca la imagen religiosa comparando la mujer con Jesús Cristo, despeinada como en la tradicción bíblica (y clásica) de la manifestación del duelo y purificadada -ella, mujer nocturna- por su voluntad de expiación, por su deseo de ser instrumento de salvación de muchos hombres al recibir la muerte por mano de uno de ellos, el apache.

\section{Conclusión.}

Un factor común a las tres pantomimas reside en la dificultad que representa atribuirles una identidad formal y de género: escena sin teatro, teatro sin acción (en el sentido estricto de la palabra), transposición literaria de una visión cinematográfica, etc. Las pantomimas abarcan, como se ha dicho en más de una ocasión, ámbitos distintos: narración literaria, poesía, danza, cinematografía, representación del concepto por una imagen o por una figura retórica: a fin de cuentas se trata de recursos y objetos que se remontan a la palabra y a la capacidad cinética.

Aunque compleja y de difícil definición la cuestión formal no se puede separar del aspecto estilístico; en este ámbito se puede añadir una última observación. Las tres pantomimas tienen como núcleo de base el enunciado mínimo, fundamento de toda narración; intentemos individuarlo en cada una de ellas. Las danzas de pasión : 'el público observa a dos personajes, Adán y Eva (que están en la escena).'. El garrotín : 'una mujer baila'. La danza de los apaches: 'un hombre y una mujer bailan'. 
Cada obra es por tanto una amplificación del enunciado mínimo, circunstancia absolutamente normal en el caso de un texto narrativo cuyas modalidades de desarrollo suelen seguir una direccionalidad lineal ${ }^{14}$.

Invocando la ayuda de los recursos teatrales, Ramón Gómez de la Serna crea una proyección espacial que tiene elementos de simultaneidad ajenos a la técnica narrativa tradicional y aun más al ámbito de la prosa lírica.

Es más; la obra pretende representar la acción pero ésta va palautinamente configurándose como 'pre-texto' ${ }^{15}$ para la narración; así es como se configura ,pues, el 'baile' que aparece en el título de las tres pantomimas. La amplificación del enunciado mínimo conlleva la manifestación del centro temático. Por ejemplo: 'un hombre y una mujer bailan' es el enunciado mínimo, que incluye el pre-texto y que introduce los conceptos que se van a expresar: sacrificio, amor, muerte. Evidentemente este proceso se hace posible gracias al planteamiento simbólico de la obra; sólo de esta forma es lícita la posibilidad inmediata de identidad "baile"= "experiencia, vivencia, ritual". La "mirada nueva" de Ramón hace que lo simbólico adquiera matices propios y originales. La elección léxica, el estilo del Autor producen un objeto literario en el cual, en más de una ocasión parece aflorar una sensibilidad tremendista; por otra parte se revela una minuciosa observación naturalista de los acontecimientos, sin temor ninguno a lo que comúnmente entendemos por 'fealdad'. Se ha sugerido anteriormente el término de 'ex- centricidad' estética; y bien, creo que de esto se trata. Porque el fenómeno que en el naturalismo asumiría un exclusivo interés científico adquiere en Ramón Gómez de la Serna un valor estético , mucho más amplio porque abierto a la visión sujetiva y no racionalista a través del prisma que los 'ojos nuevos' ven atravesado por un rayo de luz, nueva ella misma.

Destaca en Ramón la capacidad de ruptura consciente en favor del conocimiento (porque al fin y al cabo Ramón expresa la urgencia del conocimiento), ruptura que recuerda, dejando salvas distinciones y diversidades, el acto de romper el espejo que tantas veces tendría que fragmentarse en las manos inquietas de la Vanguardia.

\footnotetext{
14 Independientemente de la presencia de elementos de elipsis, prolexis, o pausas y de las intervenciones de la voz narrante.

15 Y también con características del "paratexto" según lo entiende G. Genette en Palimpsestos, ( Taurus, Madrid 1989; I ed, Ed. du Seuil, Paris 1962)
} 


\section{BIBLIOGRAFIA}

R. Gómez de la Serna (Tristán), Tapices, Imprenta Aurora, (Madrid 1913).

-"Palabras en la rueca", Prometeo XXXV (1911), s.p.

-" El concepto de nueva literatura", Prometeo VI, (1909).

G. D'Annunzio, Laudi , (1903-1912), ed. Mondadori, (Milano 1983).

M. Palenque, El teatro de Gómez de la Serna. Estética de una crisis, Cuadernos de Comunicación 9, Alfar, ( Sevilla 1992).

A. Martínez- Collado, Ramón Gómez de la Serna, Una teoría personal del arte. Antología de textosde estética y teoría del arte, Tecnos, (Madris 1988).

A. Soria Olmedo, Vanguardismo y crítica literaria en España, Istmo, (Madrid 1988).

L. García Montero, Poesía, cuartel de invierno, Hiperión, (Granada I ed. 1987).

G. Genette, Figures III, éd, du Seuil, (Paris 1972).

-Palimpsestos. La literatura en segundo grado, Taurus, (Madrid, 1989); I ed. , du Seuil, (Paris 1962.) 